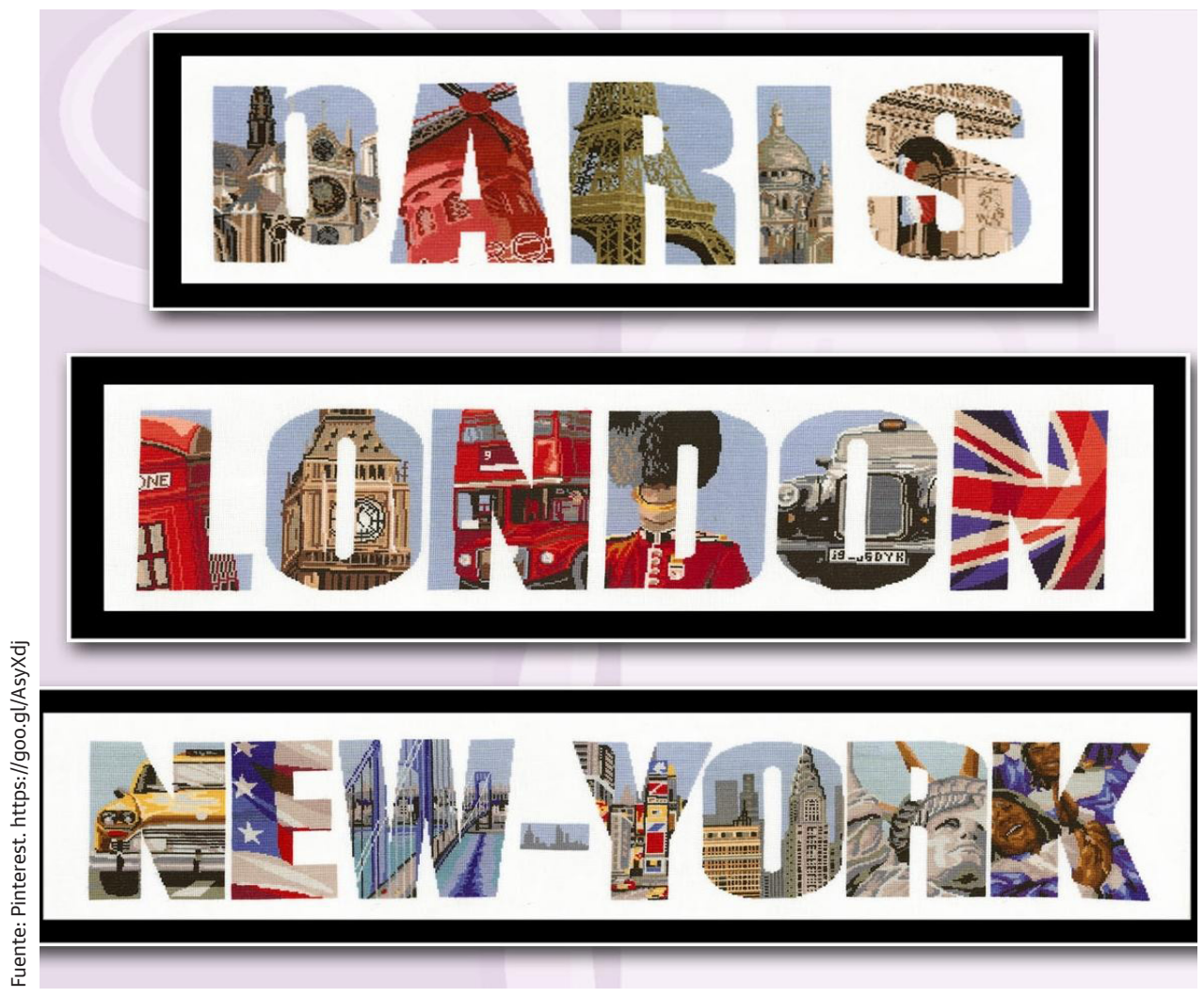

\title{
LAS ASOCIACIONES "MARCA PRODUCTO" $Y$ "MARCA CIUDAD" COMO ESTRATEGIA DE "CITY BRANDING" Una aproximación a los casos de Nueva York, París y Londres
}

ALLIANCES BETWEEN BRANDS AND CITIES AS A NEW COMPETITIVE STRATEGY TO DEVELOPE A CITY BRAND. A look at city branding in New York, Paris and London

Olga Heredero Díaz / olga.heredero.diaz@ucm.es Miguel Ángel Chaves Martín / machaves@ucm.es UNIVERSIDAD COMPLUTENSE DE MADRID 


\section{RESUMEN}

En los últimos años, las asociaciones entre marca producto y marca ciudad han tenido un creciente protagonismo, tanto en el lanzamiento de nuevos productos por parte de las empresas, como en las estrategias de gestión urbana.

En el contexto socioeconómico actual, en el que las ciudades se han convertido al igual que las empresas e instituciones públicas y privadas en parte de un mercado globalizado, todas ellas buscan a través de sus marcas, un elemento de diferenciación que les provea de una ventaja competitiva. Es por ello que las asociaciones entre las marcas producto y sus ciudades de origen se incluyen en el proceso de brandificación de estas últimas como una nueva fórmula para superar la incertidumbre derivada de la crisis financiera mundial. Un modo de actuar que se adivina exitoso siempre y cuando dichas uniones sean concebidas como alianzas estratégicas a largo plazo, y no como meras acciones de naming en las que el nombre de la ciudad y la marca del producto figuren juntos sin más.

No obstante, apenas hay trabajos que analicen la justificación de dichas asociaciones, así como de los beneficios y ventajas que su utilización supone, tanto para las marcas producto como para las marcas ciudad. En este sentido, el presente artículo resume las principales teorías que justifican el porqué de dichas uniones desde la perspectiva del comportamiento del consumidor, así como las estrategias a las que responden, a la par que analiza la consolidación de las marcas Nueva York, París y Londres a través del uso de un estilo de vida propio y diferenciado como reclamo para la creación de asociaciones entre marca producto y marca ciudad.

PALABRAS CLAVE

Marca ciudad, city marketing, city branding, cobranding, alianza de marca, brandificación, efecto "made in".

\section{ABSTRACT}

In recent years, associations between product brand and city brand have experienced an increasing role in both the launch of new products by companies, as well as in urban management strategies.

In the current socioeconomic context in which cities, companies, private and public institutions have all become part of the globalized market, they all look for a distinctive element through their brands, that will provide them with a competitive advantage. For that reason, associations between the product brand and its city of origin are included in that city's branding process as a new formula to overcome the uncertainty from the global financial crisis. An approach supposed to be successful provided that such associations are conceived as long-term strategic alliances, and not as mere naming actions for the city name and product brand to just simply appear together and nothing else.

Yet, there are very few studies that analyze the reasons for these associations, as well as the benefits and advantages resulting from their use to both the product brands and the city brands. In this regard, this article summarizes the main theories that justify the reason for such alliances from the perspective of consumer behavior, as well as the strategies that they are responding to, while also analyzing the consolidation of the New York, Paris, and London brands through the use of a distinctive and particular city lifestyle as claim to create these associations between the product and the city brand.

KEYWORDS

City brand, City-marketing, City-branding, cobranding, brand alliance, branding, "made in" effect. 


\section{INTRODUCCIÓN}

La ciudad como marca definida como "el nombre, término, símbolo o diseño, o combinación de ellos que trata de identificar las características de la ciudad y diferenciarla de otras ciudades" (Loreto y Sanz, 2005: 6), y su relación con el valor de marca, ha sido objeto de estudio de numerosos autores. Entre ellos, D. Aaker (1991), que plantea que la identificación y diferenciación son básicas para que las ciudades resulten más atractivas que su competencia, de forma que entendida como tal, la marca ciudad adquiere una dimensión simbólica que se traduce en un beneficio social y económico (valor de marca):

(...) un conjunto de activos y pasivos vinculados a la marca, su nombre y símbolo, que incorporan o disminuyen el valor suministrado por un producto o servicio (...) (Aaker, 1991: 18).

En esta misma línea, M. Dachevsky (2011), equiparando la marca ciudad a una marca producto, cuantifica las variables de las que depende el valor de marca mediante la siguiente fórmula:

\section{$P=(F+S) \times C$}

Donde producto ("P") es igual a una serie de componentes físicos ("F") más otros de carácter semántico ("S"); el primer término se refiere a los costes, insumos, posibilidades tecnológicas, impacto ambienta, etc. El segundo a la comunicación, la percepción y los vínculos que se establecen con los usuarios de alta calidad, lo que significa satisfacción para todos los involucrados en la producción, que se traduce en valor. Esto multiplicado por el acceso a distintos mercados a través de múltiples canales ("C") garantiza la competitividad del producto y su éxito (Dachevsky, 2011: 91).

No obstante, en la bibliografĩa específica existen tres formas distintas de concebir la marca ciudad: ciertos autores (Blain, Levy y Brent Ritchie, 2005) la definen como la identidad que los responsables de marketing deciden y comunican, mientras que para otros, sería el conjunto de actitudes y percepciones que se crean en la mente del consumidor (Baker, 2007). Por último, hay quién define la marca ciudad como la suma de las dos anteriores: identidad más imagen (Huertas, 2011).

En consecuencia, de estas tres perspectivas derivarían las tres tipologías en las que es posible clasificar la mayoría de los análisis de la marca ciudad. Por un lado, destacan los estudios que analizan las marcas por ellas mismas: sus nombres, logotipos, simbología, identidad, valores, funciones y significados. Por otro, los que se basan en las asociaciones y relaciones que crean las marcas en sus públicos y, por último, los que analizan los aspectos gráficos y su simbología conjuntamente con la percepción de las marcas por parte de todos sus stakeholders.

Pues bien, una vez creada la marca ciudad cabría cuestionarse cómo ha de ser gestionada. De acuerdo con Hatch y Schultz (2003), las marcas producto y las marcas corporativas difieren en varios aspectos, siendo el nivel de intangibilidad y complejidad de éstas mucho mayor (Simoes y Dibb, 2001). Por su parte, la marca ciudad y la marca corporativa se asemejan en que son diferentes a la marca producto, ¿pero significa esto que la marca ciudad debería gestionarse como una marca corporativa? Lo cierto es que no está claro.

A este respecto, existen autores que consideran que el marketing no puede aplicarse a las ciudades porque son realidades permanentes con una identidad inmutable (Girard, 1999). No obstante, son mayoría los que consideran que sí es aplicable (Kotler, 2000; Elizagarate, 2003; Anholt, 2012), e incluso que existe un paralelismo entre la gestión de la marca corporativa y la propia de la marca ciudad (véase fig. 1). De ahí, que apuesten a partir de 1993 por el desarrollo de un marketing específico para ciudades (Kavaratzis, 2007) bajo la denominación de marketing de lugares (Kotler, Haider y Rein, 1993), aunque no será hasta el año 2000 cuando cobrará relevancia en la gestión urbana (Elizagarate, 2003 y 2008). Un nuevo concepto que parte de la consideración de la existencia de dos ciudades en el entorno urbano: la ciudad externa, definida por estereotipos, y que normalmente coincide con 
la perspectiva del turista (destination brand) y, la ciudad interna (place brand), obviada hasta entonces, e integrada por el conjunto de percepciones y experiencias de los residentes en ella. Así, el éxito en la gestión de la marca ciudad consistiría en la integración de ambas ciudades (Seisdedos, 2006).

\begin{tabular}{|l|l|l|}
\hline ASPECTOS & $\begin{array}{l}\text { MARCA } \\
\text { CORPORATIVA }\end{array}$ & $\begin{array}{l}\text { MARCA } \\
\text { CIUDAD }\end{array}$ \\
\hline Propiedad & $\begin{array}{l}\text { Accionistas, } \\
\text { empresariado }\end{array}$ & $\begin{array}{l}\text { Ciudadanos e } \\
\text { instituciones }\end{array}$ \\
\hline Alta Dirección & $\begin{array}{l}\text { Consejo de } \\
\text { administración }\end{array}$ & $\begin{array}{l}\text { Ayuntamiento } \\
\text { alcaldía }\end{array}$ \\
\hline Productos & $\begin{array}{l}\text { Manufacturas o } \\
\text { servicios }\end{array}$ & $\begin{array}{l}\text { Servicios } \\
\text { públicos }\end{array}$ \\
\hline Clientes & Consumidores & $\begin{array}{l}\text { Ciudadanos, } \\
\text { inversores, } \\
\text { visitantes }\end{array}$ \\
\hline $\begin{array}{l}\text { Competidores } \\
\text { y cooperantes }\end{array}$ & Otras empresas & Otras ciudades \\
\hline
\end{tabular}

Figura 1. Paralelismos entre la gestión de la marca corporativa y la marca ciudad.

Fuente: Muñiz (2010) adaptado de Fernández Güell (2006) en "Marketing de ciudades y place branding", Pecvnia, Monográfico, 131.

Sea como fuere, lo cierto es que puede definirse el marketing de ciudades como una política activa integrada por un conjunto de actividades orientadas a que las ciudades realicen una oferta adecuada a la demanda de todos sus públicos mediante el desarrollo de una estrategia acorde con la identidad que singulariza cada ciudad, lo que permite diferenciarla. Y una de las formas como el marketing puede implementarse en la ciudad es mediante el branding urbano (city branding), término que hace referencia al proceso de branding aplicado a las ciudades (Kavaratzis, 2004), es decir, al proceso de creación y gestión de las marcas ciudad y en el que la participación ciudadana es esencial (la marca ciudad se construye de dentro hacia fuera).

Y a la falta de consenso en la teoría, se añade la confusión terminológica derivada del uso de multitud de denominaciones distintas para referirse a la cooperación entre marcas de lugar con marcas producto o corporativas, que han dado lugar a una categoría híbrida de marcas con "nombre" de producto y "apellido" de ciudad, tales como Pepe Jeans London, Bourjois París, Natura Bissé Barcelona, Loewe Madrid, Prada Milano, Maybelline New York, y un largo etcétera, que resulta difícil clasificar.

En un intento por poder hacerlo, se ha de señalar que en este texto el término alianza de marca se refiere a todas las circunstancias en que se presentan dos o más marcas individuales, productos u otro distintivo de los implicados, de forma conjunta al consumidor (Simonin y Ruth, 1998). Un concepto que abarca distintas alternativas (Desai y Keller, 2002): desde el lanzamiento de un nuevo producto en el que se incluyen dos marcas ya existentes (por ejemplo, el atún claro Calvo en aceite de oliva Carbonell), hasta la presentación de de una marca con componentes de otra (por ejemplo, los dispositivos móviles que Nokia comercializa con Windows Phone de Microsoft).

En consecuencia, es importante diferenciar las alianzas estratégicas de marca, que serían los acuerdos de colaboración entre marcas para alcanzar un mismo objetivo (Cerviño, 1996), del comarketing, entendido como las herramientas para la puesta en marcha de esos acuerdos usando recursos comunes, y que puede aplicarse a cualquiera de los elementos del marketing mix o a todos en conjunto'.

De la misma forma, hay que distinguir entre acciones de marketing conjuntas como pueden ser la publicidad cooperativa, el partnership, copatrocinio, emplazamiento de producto, coopetición, licencias o acciones de comunicación cruzadas, de una alianza de marca ${ }^{2}$.

1 Una definición más completa, así como una clasificación ejemplificada de las variantes de comarketing puede consultarse en Torreblanca Díaz, F., Lorente San Juan, F., López Tortosa, R., Blanes Nadal, C. y Juárez Varón, D. "Comarketing como herramienta estratégica empresarial", 3C Empresa, Investigación y pensamiento crítico, no 10 (enero 2013), pp. 1-14. Última consulta el 4 de diciembre de 2014.

2 Dicha diferenciación aparece recogida en Alcaide, J. C. y Chávarri, I. "El comarketing como arma de presente y estrategia de futuro", Marketing y Ventas para Directivos, Año XXIV, no 260 
Otro término relativo a las asociaciones entre marcas, pero menos amplio que el ya citado de alianza estratégica entre aquellas es el de cobranding, que puede definirse como la asociación de dos o más productos para formar un tercero con identidad propia (Park, Jun y Shocker, 1996), o desde un enfoque más marketiniano, como "la combinación de dos o más marcas conocidas en una oferta, donde cada marca espera que la otra fortalezca la preferencia de marca o la intención de la compra de su público objetivo" (Kotler, 2000: 121).

No obstante, en el caso de las asociaciones entre marcas producto y marcas ciudad, nos encontramos ante alianzas simbólicas (no físicas), que se usan para proporcionar valor añadido a los consumidores a través de la transferencia de las asociaciones de cada una de las marcas involucradas y, que en la mayoría de casos, pueden englobarse en una variante del cobranding que D. Aaker define como "un fenómeno específico en el respaldo de las marcas denominado respaldo por nombre vinculado" (Aaker, 2011: 131). Un concepto que se aproxima bastante a lo que Wally Olins define dentro de las estrategias de branding ${ }^{3}$ como endorsed o marca respaldo: aquella en la que la marca corporativa respalda de forma explícita a todas sus marcas producto desencadenando una retroalimentación de significados y reforzando sus vínculos: la marca corporativa aporta visión, confianza y capacidad, al tiempo que se nutre del territorio y atributos específicos de cada marca a la que avala.

(2010), pp. 8-18. Última consulta el 23 de noviembre de 2014.

3 W. Olins defiende la existencia de tres tipos de estrategias de branding: el ya citado modelo de la marca respaldo (Endorsed House), el modelo monolítico (Brand of the House), que consiste en el uso de una única marca a nivel corporativo y comercial en todos los productos, servicios y líneas de negocio y, por último, el modelo de marcas independientes (House of Brands), opuesto al anterior, en el que coexisten marcas distintas e independientes para diferentes líneas de negocio y a nivel corporativo. No obstante, cada vez son más las marcas que optan por una cuarta estrategia de branding, el modelo asimétrico o mixto, según el cual se emplean diferentes modelos de arquitectura de marca para las diferentes líneas de negocio.

\section{METODOLOGÍA}

El objeto de estudio de este texto son las asociaciones entre marcas producto y marcas ciudad, cuyo auge en los últimos años está estrechamente vinculado al fenómeno de la revaloración de la gestión de los intangibles como respuesta a la necesidad de las ciudades, empresas, organizaciones e instituciones públicas y privadas para diferenciarse de forma competitiva en un mercado cada vez más globalizado.

En este sentido, el objetivo de este artículo es profundizar mediante una revisión bibliográfica en el conocimiento sobre los efectos de las asociaciones entre las marcas producto y las marcas ciudad, así como en los beneficios de la gestión de marcas asociadas a lugares con relación a las tradicionales marcas asociadas a productos y/o servicios. Para ello se ha recurrido a la aplicación de la técnica cualitativa del estudio del caso a los procesos de brandificación llevados a cabo por Nueva York, París y Londres en su consolidación como marcas ciudad a través del uso de un estilo de vida propio y diferenciado como reclamo para la creación de asociaciones entre marca producto y marca ciudad.

La elección de estas tres ciudades responde al hecho de que durante la búsqueda de ejemplos de asociaciones entre marcas producto y marcas ciudad para la elaboración de este texto, se ha comprobado que son las ciudades con mayor trayectoria en lo que a las colaboraciones entre marcas producto y marcas ciudad se refiere.

\section{EL POR QUÉ DE LAS ASOCIACIONES ENTRE MARCAS PRODUCTO Y MARCAS CIUDAD}

Con demasiada frecuencia, la construcción de la marca ciudad se limita a su promoción exterior (casi siempre turística o como localización empresarial) a través de un logotipo, un eslogan o una campaña de publicidad, cuando en realidad debe implicar un enfoque integral y a largo plazo, del que el diseño de la imagen es solo la fase de comunicación de un proceso estratégico que va mucho más allá (Virgo y De Chernatony, 2006). 
Un proceso complejo en el que el nombre de la ciudad se convierte en el principal componente de la marca ciudad, puesto que su singularidad permite que se la pueda identificar, reconocer y diferenciar.

Sin embago, con el nombre no es suficiente. Una marca ciudad ha de sintetizar un concepto, un modelo urbano determinado que para tener éxito necesita establecer con sus públicos vínculos emocionales que le permitan adaptarse a largo plazo a sus necesidades. Para ello, la imagen de la marca ciudad entendida como el resultado de las percepciones de sus stakeholders (Fombrun, 1996; Hatch y Schultz, $2003)^{4}$ ha de despertar un sentimiento de identificación con sus valores, su estilo de vida, etc., puesto que los consumidores buscan en las marcas una experiencia integral mediante la que sentirse parte de un grupo y con la que construir su propia identidad. En consecuencia, al optar por una marca ciudad en la que residir, invertir o visitar, necesitan encontrarse a sí mismos en ella.

De todo ello puede deducirse que el proceso de transferencia recíproca de imagen entre dos objetos es el soporte idóneo para una estrategia de marca compartida entre un lugar y un producto. De hecho, son infinitas el tipo de relaciones que conocemos entre productos y ciudades (L’Oreal París, Breil Milano, Custo Barcelona, Rimmel London, etc.) y, en todas ellas, la aparición del nombre de la ciudad genera una serie de asociaciones en la mente del consumidor que irremediablemente se trasladan al producto, ya sean connotaciones positivas o negativas. A este respecto, lo que cabe preguntarse en cada caso es si realmente se trata de una variante de co-

4 Una aproximación al concepto de imagen de marca la encontramos también en J. Villafañe (1999), que la define como la integración en la mente de los públicos de interés de una marca de todos los mensajes emitidos por ésta en su relación con ellos. Por su parte, G. Dowling (1994) señala que dicha imagen es la impresión total (creencias y sentimientos) que una organización genera en la mente de sus stakeholders. Dicho lo cual, podría entenderse la imagen de marca como el resultado de la interacción de todas las experiencias, creencias, conocimientos, sentimientos e impresiones que el público tiene respecto a una empresa. branding, de un simple proceso de naming o de algún otro tipo de estrategia.

Diferentes teorías han tratado de explicar cuáles son los fundamentos que sostienen dichas uniones, siendo el denominador común de todas ellas la idea de que el consumidor traslada los conocimientos, asociaciones y actitudes de un elemento conocido, en este caso la marca ciudad, a un elemento desconocido, la marca producto.

Es por ello que entendido el cobranding como un acuerdo win-win entre marcas, en la gestión de estas alianzas la elección del socio adecuado es fundamental. En este sentido, James, Simonin y Ruth (1998) apuntan que el consumidor valorará más positivamente aquellas alianzas que resulten más coherentes con las marcas involucradas, de forma que cuanta más alta sea la percepción de calidad de las marcas originales, más favorables serán las actitudes ante la alianza.

Este razonamiento adopta perspectivas distintas según la teoría desde la que se oriente, pero la mayoría coinciden en que supone la creación de un valor añadido superior al que podrían conseguir las marcas que integran la alianza por separado (Cruz y Cerviño, 1996). Sin embargo, tal y como señalan Aaker (1991) y Kapferer (1994), estas alianzas pueden tener efectos neutros, crear asociaciones o atributos negativos e incluso perjudicar el valor o imagen de la marca ciudad en su contexto original, puesto que estas uniones afectan a las percepciones que los consumidores tienen sobre las dos marcas originales de forma independiente (Kumar, 2005).

Otro aspecto a tener en cuenta a la hora de valorar la posibilidad de incluir el nombre de un territorio en una marca producto es el denominado efecto Made in, también conocido como Country of Origin Effect (COE), puesto que se ha confirmado que el poder del Made in es más potente y valioso que el del Made by, es decir, que el país creador del producto genera asociaciones más fuertes en la mente del consumidor que el país donde se fabrica (Cerviño, Sánchez y Cubillo, 2005). Lo que cobra suma importancia en un mercado global en el que las grandes 
empresas con sus economías a escala deslocalizan su producción para reducir costes. Y es que algunos países/ciudades agregan un atractivo a sus productos sólo por su procedencia, un efecto halo que han sabido aprovechar las marcas para promocionarse y que, pese a ser más fácilmente vinculable a la marca país, ha dado lugar a productivas uniones entre marcas producto y marcas ciudad basadas en alusiones al estilo de vida para generar identificación y pertenencia.

De hecho, recientes estudios sobre la imagen país de los consumidores de países en vías de desarrollo confirman que su preferencia por los productos y marcas de países desarrollados se fundamenta en que los asocian a una mayor calidad, un estatus, una imagen y un estilo de vida diferente y superior a la del resto de consumidores (Zhou y Belk, 2004; Zhuang y otros, 2008). Lo que explicaría que los Ayuntamientos de Barcelona y Madrid, entre otros, hayan establecido acuerdos para potenciar sus marcas ciudad incluyendo sus nombres junto al de marcas comerciales, cuyas tiendas se convierten así en puntos de venta de la marca ciudad implicada ${ }^{5}$.

Sin embargo, también existe el fenómeno inverso, de forma que algunas regiones construyen su imagen a partir de las imágenes de productos y/o empresas concretas instaladas en su territorio. ¿Sería posible entonces utilizar la imagen positiva de la marca de un producto y transferirla al lugar donde dicho producto es elaborado? Existen notables ejemplos de ello, como es el caso de La Rioja y su campaña "La tierra con nombre de vino". Sea como fuere, lo cierto es que una vez que se ha creado la marca ciudad, ésta se debe comunicar con acciones que permitan y animen a instituciones o empresas privadas a usar su marca y logotipo.

Es importante, no obstante, establecer una normativa que regule dichas asociaciones y que

5 En el 2008 el Ayuntamiento de Barcelona firmaba un acuerdo con Mango para que la marca llevase el nombre de la ciudad en las bolsas y en algunas piezas de comunicación de la marca. "La firma de este convenio es un paso más para vincular la marca Barcelona a referentes internacionales de prestigio y de innovación", Jordi Hereu, alcalde de Barcelona en 2008. evite que la marca ciudad resulte perjudicada. Así, por ejemplo, el Ayuntamiento de Barcelona es quién estudia las solicitudes que la Oficina Española de Patentes y Marcas (OEPM) recibe para utilizar el nombre de la ciudad; alrededor del $90 \%$ obtienen el permiso y, en caso contrario, es la OEPM quien decide, aunque se vigila que no se creen marcas que se puedan confundir con un servicio público. Iniciativas a las que tampoco es ajeno el Ayuntamiento de Madrid, que en su Boletín Oficial del 4 de mayo de 2011, promovía la inclusión del nombre de la ciudad en empresas relacionadas con el sector de la moda ${ }^{6}$.

\section{UN ESTILO DE VIDA DIFERENCIADO COMO RECLAMO PARA LAS ASOCIACIONES ENTRE MARCAS PRODUCTO Y MARCAS CIUDAD: EL PROCESO DE "BRANDIFICACIÓN" DE NUEVA YORK, PARÍS Y LONDRES}

Quizá el cambio más sorprendente en el panorama corporativo en los últimos años sea el hecho de que, como resultado del dinamismo y la complejidad del entorno, incluso competidores naturales se han dado cuenta de que lo mejor para ellos es cooperar en la satisfacción de las necesidades de un consumidor complejo, infiel y exigente, que instalado en la cultura del yo y del "no sin mis amigos", les reclama "ventajas de verdad" y que está cansado de recibir "más de lo mismo".

Una espiral de colaboraciones a la que no son ajenas las asociaciones entre marca ciudad y marca producto. En este sentido, son Nueva York, París y Londres las ciudades que han desarrollado una política de colaboración marca ciudad/marca producto más prolífica.

No obstante, llama la atención que pese a ser

\footnotetext{
6 "Uno de los medios más eficaces para contribuir a mejorar la proyección internacional de la imagen de la ciudad y por ende a estimular la actividad económica, comercial y turística de Madrid consiste en la concesión de ayudas a agentes vinculados con el sector de la moda (...) El Ayuntamiento apoyará a las personas físicas o jurídicas relacionadas con el sector de la moda con residencia o establecimiento permanente de diseño, confección o venta en la ciudad de Madrid o que tengan el nombre de Madrid en su marca o logo comercial (...)". Boletín Oficial del Ayuntamiento de Madrid (4 de mayo de 2011).
} 
las más reclamadas por las marcas comerciales, ni Nueva York, ni París, estén presentes en el top ten de los rankings de marca ciudad más renombrados ${ }^{7}$, aunque sí ocupan las primeras posiciones en el informe "Cities of Opportunity 2014", publicado por la consultora PricewaterhouseCoopers en mayo de 2014, tras analizar los aspectos más atractivos de las ciudades en cuanto a su habitabilidad y relevancia económica.

A continuación, se describe el modelo de brandificación seguido por estas tres ciudades, cuya marca ciudad ha sido pieza clave para adquirir el posicionamiento que ostentan como lugares con una forma de vivir única, que las hace tremendamente atractivas para la constitución de asociaciones con marcas producto, debido a que lo que éstas buscan para establecer tales uniones es que la ciudad posea un estilo de vida específico y reconocible con el que sus productos puedan establecer asociaciones emocionales y simbólicas en la mente del consumidor. Y en este sentido, Nueva York, París y Londres son prácticamente las únicas ciudades que han conseguido crear un estilo propio reconocido internacionalmente.

No importa que no sean ciudades seguras, ni eco-responsables, o que sus ciudadanos no sean amables, precisamente algunas de las variables que miden los rankings de marca ciudad, sino el hecho de que cualquier persona, en cualquier lugar del mundo, podría identificar una de sus calles con solo echar un vistazo a los personajes que circulan por ellas. Y esto es lo que buscan las marcas, simplificar las decisiones y poner etiquetas a las imágenes de las ciudades que todos tenemos en la cabeza.

\subsection{Nueva York: un estilo de vida muy "cool"}

Si bien la titularidad de la gestión de la marca es pública y compartida entre la Agencia de Turis-

7 En el City Rep Track 2013, Londres ocupa la novena posición, Nueva York la vigésimo primera y París la vigésimo segunda. La lista completa de los resultados está disponible en: http://www. reputationinstitute.com/frames/events/2013_City_RepTrak_Press_ Release.pdf mo del Estado de Nueva York, el gobernador de la ciudad y la Alcaldía, lo cierto es que en la práctica, es una organización privada no lucrativa, la NYC \& Company, la responsable activa de su gestión.

La organización está formada por más de 2.000 empresarios y negocios de la ciudad pertenecientes a sectores muy diversos (turismo, ocio, cultura, entretenimiento...) que han desarrollado una estrategia de marca ciudad que va más allá de un eslogan o una campaña de publicidad, y que se concreta en un proceso de branding que busca aunar su identidad con los intereses de sus visitantes, ofreciendo una amplia y singular oferta de atractivos turísticos y culturales que generan experiencias únicas.

Para ello, la ciudad se promociona como un lugar lleno de energía y dinamismo (la ciudad que nunca duerme), de oportunidades, de color, luz y contraste. Una ciudad cosmopolita rebosante de diversión y diversidad (de barrios, de culturas, de actividades, de gentes, etc.): la capital del mundo.

Lo cierto es que la marca Nueva York se hizo internacional con la campaña de finales de los años setenta "I love New York", que consiguió cambiar la imagen de la ciudad, por entonces sumida en una de sus mayores crisis fiscales y con unos niveles altísimos de inseguridad ciudadana, lo que había supuesto el descenso del turismo y de las inversiones empresariales. El objetivo era que la gente percibiera Nueva York no como una gran ciudad, con todos los problemas que eso supone, sino como un lugar del que disfrutar y en el que poder vivir. De este modo, la campaña estaba dirigida, tanto a recuperar el turismo que se estaba perdiendo, como a todos los habitantes del Estado de Nueva York.

Originalmente debía durar únicamente un par de meses, pero su éxito la ha hecho perdurar con el paso de los años como una marca de identidad de la ciudad de Nueva York. Tanto es así, que el eslogan es el dominio de la página web de la Agencia de Turismo del Estado de Nueva York (www.iloveny.com), y las camisetas blancas con el logo estampado siguen siendo a día de hoy uno de los recuerdos de Nueva York 


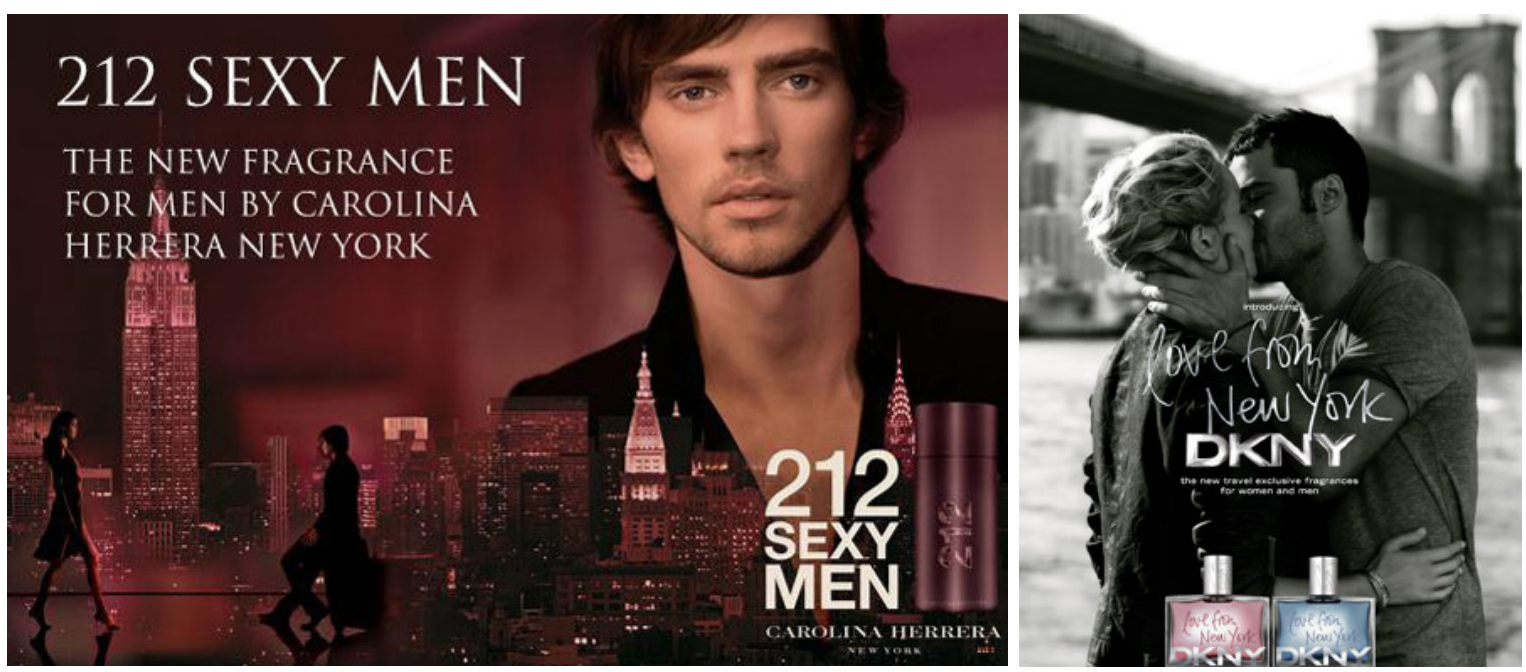

Figura 2. Campañas de publicidad de Carolina Herrera New York y Donna Karan New York en las que la ciudad y su estilo de vida se emplea como reclamo.

Fuente imagen izda: http://fimgs.net/images/secundar/o.428.jpg / Fuente imagen drcha: http://beauty.blog.nl/files/2009/08/dkny.jpg

más vendidos. Es más, incluso tras el atentado del 11S se retomó el mítico eslogan adaptándolo a la nueva realidad y con el objetivo de fortalecer la identidad de la marca ciudad: "I love NY more than ever".

En el año 2007, la Alcaldía puso en marcha la primera campaña de comunicación global en la historia de la marca. Una campaña $360^{\circ}$, multilingüe y que incluía publicidad en TV, prensa, medios online y publicidad exterior en 10 países de 4 continentes. La campaña "Esto es la ciudad de Nueva York" se inspiraba en la amplia variedad de experiencias que la ciudad ofrece a sus visitantes, y que no se encuentran en ningún otro lugar del mundo. El eje central era un spot de TV en el que aparecían iconos de los 5 distritos de la ciudad como el estadio de los Yankees, Times Square, Coney Island, el Ferry de Staten Island y el Unisphere, con el fin de promover a la vez la identificación de los residentes de la ciudad con su marca.

La campaña formaba parte de un ambicioso plan a largo plazo de las autoridades locales, que pretendían alcanzar en 2015 los 50 millones de visitas anuales. Así pues, tras centrarse durante estos años en el turismo, en 2011 las instituciones responsables de la gestión de la marca Nueva York decidieron que ya era hora de que sus públi- cos percibieran a la ciudad no sólo como un lugar para visitar, sino también como un buen sitio para vivir, para trabajar y para hacer negocios.

En consecuencia, este ha sido el objetivo de sus últimas campañas, proyectar el estilo de vida neoyorquino y tratar de combatir la imagen generalizada de que su clima es de los peores de EE.UU., mostrando para ello una ciudad vital, dinámica, palpitante y emocionante.

Una ciudad vibrante que se reinventa cada año y con un estilo de vida sofisticado, que se promociona a través de las más de 60 producciones anuales entre cine y TV que se ruedan en la ciudad.

Un estilo de vida muy "cool" propio de profesionales de éxito de clase media, con el tiempo libre suficiente para disfrutar de las múltiples posibilidades de ocio que la ciudad les ofrece (espectáculos, restaurantes, actividades culturales o de ocio y deporte al aire libre, paseos por Central Park, exposiciones de fotografía en galerías de arte,...) con el que la ciudad ha conseguido consolidar sus asociaciones con marcas producto como Carolina Herrera New York, Maybeline New York, DKNY, etc., que no solo la incluyen en su denominación, sino que la promocionan a través de campañas de publicidad en las que casi siempre incluyen imágenes de sus calles. 


\subsection{París: un estilo de vida muy "chic"}

La marca París se gestiona a través de Oficina de Turismo y Congresos de París, un organismo público que depende institucionalemente del Ayuntamiento de la ciudad y de la Cámara de Comercio e Industria de París.

Si bien, aunque la gestión es pública, promueven la colaboración con entidades privadas animando (previo pago de la cuota anual correspondiente) a los establecimientos o negocios de la ciudad a que soliciten el sello/logotipo institucional de Establecimiento Adherido.

La estrategia para la creación de la marca ciudad ha sido la priorización de la oferta cultural como atributo esencial de la marca, tal y como se recoge en el informe " 40 ans de Turisme a Paris" editado por la Oficina de Turismo y Congresos de París en 2011 con motivo del cuadragésimo aniversario de su fundación, que recoge la trayectoria de la promoción de la ciudad a lo largo de este período.

En otras palabras, mientras que Nueva York se promociona como un destino ideal para el ocio, la diversión y entretenimiento, París lo hace como una de las capitales culturales del mundo, a pesar de que no son muchas las campañas que publicitan la ciudad, quizá porque sus autoridades son conscientes de que no las necesita. Con la Torre Eiffel como símbolo de la ciudad, París es una marca rentable desde hace tiempo para todas aquellas marcas que buscan generar en el consumidor asociaciones con el glamour y la elegancia.

Capital de la moda por excelencia, la ciudad potencia su imagen como cuna del estilo y del buen gusto, de ahí que buena parte de las marcas que se alían con la ciudad pertenezcan a la industria de la moda y de la cosmética/belleza.

No obstante, si bien a menudo lo que lo que aporta la marca París es exclusividad y lujo (calidad y excelencia), en otras ocasiones se alude a una elegancia despreocupada, a una sencillez sofisticada y urbana.

La ciudad ha sabido reinventarse y a día de hoy combina en su estilo lo antiguo con lo moderno, siendo el resultado una ciudad multifacé- tica con barrios de características muy diversas y con un estilo en el que se entremezclan el lujo y la suntuosidad de sus palacios y monumentos, con el glamour de las boutiques de las mejores marcas del mundo y la vida bohemia de sus cafés. Un maridaje casi perfecto entre la exclusividad y el lujo (calidad y excelencia) con la elegancia de la sencillez sofisticada.

El resultado, no podría ser otro que el encantador y coqueto "chic" francés que atrae a marcas como L’Oreal París, Lancôme París, Paco Rabanne París, Lanvin París, etc.
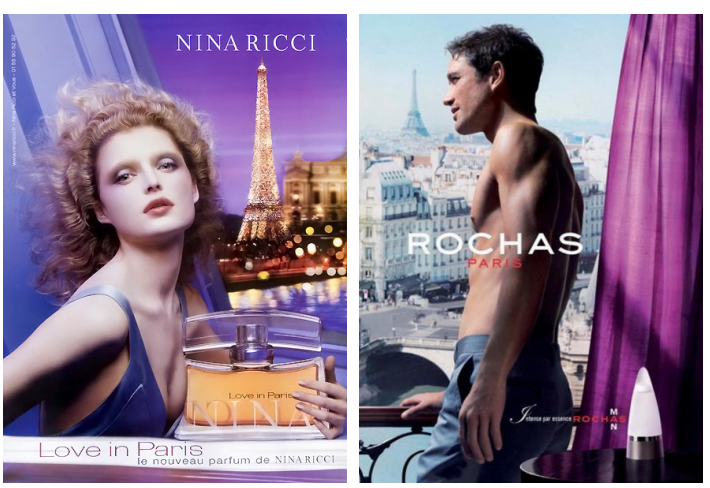

Figura 3. Campañas de publicidad de Nina Ricci París y Rochas París en las que la ciudad se emplea como reclamo para generar asociaciones entre la marca producto y la marca ciudad.

Fuente imagen izda: http://www.vanilla.kiev.ua/userfiles/images/NINA-RICCI-LOVE-IN-PARIS-2.jpg

Fuente imagen dcha: http://www.unperfume.es/images/ROCHAS-MAN-IMATGE_ad_l.jpg

\subsection{Londres: un estilo de vida muy "british"}

La gestión de la marca Londres es pública y depende de la Alcaldía de la ciudad, que la coordina a través de la Oficina de Turismo de Londres (VisitLondon). A su vez la promoción turística de la ciudad depende de la Oficina de Información Turística de Londres (BLVC), un centro gestionado por VisitBritain, la Oficina Nacional de Turismo Británico, como una oficina integral para promocionar el turismo, tanto en la ciudad como en toda Gran Bretaña. Además, algunos distritos y barrios londinenses poseen sus propias oficinas de información turística. 
No obstante, las autoridades han creado, como en el caso de Nueva York, una entidad público-privada sin ánimo de lucro para la promoción de la ciudad. Se trata de London \& Partners, que se ha constituido como un organismo encargado de asesorar a todas las empresas que deseen invertir en la ciudad ofreciendo apoyo local a las empresas, profesionales y potenciales socios que quieran conocer las oportunidades de negocio que Londres ofrece. Está financiada por el Ayuntamiento londinense y por las aportaciones de su red de socios comerciales.

Tal y como ya se ha señalado, un mismo destino no significa lo mismo para todos sus públicos. Así, para sudafricanos y australianos, Londres es una puerta al mundo profesional, la gran oportunidad, mientras que para los españoles de los años setenta y ochenta fue en su momento una fuente de inspiración radical, y ahora, un destino turístico de fin de semana, gracias, entre otras cosas, a las aerolíneas de bajo coste.

Según el informe "Cities of Opportunity 2014" ya citado, Londres es la mejor ciudad del mundo, vencido a sus competidoras por un amplio margen, y es la única que lidera tres de los principales indicadores: la preparación tecnológica, la influencia económica y los accesos a la ciudad. En general, los encuestados la percibían como un lugar ideal para los estudios universitarios, la búsqueda de empleo y los negocios. Pero lo más importante y sorprendente es que todos consideraron que era la ciudad más conocida entre todas las que se compararon.

En consecuencia, lo fundamental para la marca Londres de cara al futuro es conservar lo que ya tiene consolidado: ser percibida como un destino ideal para el desarrollo profesional, la tendencia, la vanguardia y, en definitiva, las oportunidades y la innovación. De ahí que la Oficina Nacional de Turismo Británico, VisitBritain, junto con VisitLondon, trabajen actualmente potenciando los atributos anteriores y vinculando la ciudad a intereses como la música, cine, literatura, deporte (fútbol), moda y estudios (sobre todo del inglés).

Una fórmula que ya se empleó en la campaña del 2003, "Totally London", con la que el Ayuntamiento pretendía promocionar la gran variedad de atracciones culturales y de entretenimiento de la ciudad entre sus residentes y los turistas británicos.

Sin embargo, a pesar de su posicionamiento actual, la marca ciudad también se ha enfrentado a algunos problemas. El primero de ellos derivado del logotipo elegido por la ciudad como sede de los Juegos Olímpicos de 2012, que se cambió después de que Londres fuese designada. El resultado no convenció a nadie y desató la polémica.

Ante el revuelo generado y la poca identificación de los ciudadanos con el logotipo, las autoridades londinenses decidieron crear una identidad de marca clara que sirviera para promocionar la ciudad antes y después de las Olimpiadas de 2012. El proyecto tenía cuatro objetivos básicos: crear una marca única para Londres, definir la visión para la ciudad más allá de los Juegos Olímpicos del 2012, conectar a todas las instituciones y organizaciones públicas de la ciudad en torno al nuevo posicionamiento e identidad y, por último, integrar la promoción internacional de la capital dentro de la estrategia de gobierno municipal.

Para ello, la nueva marca se ha puesto al servicio de aquellas organizaciones que representan los intereses de la ciudad, tanto en el Reino Unido, como a nivel internacional, potenciando así la brandificación de la ciudad.

Un reclamo al que no se han resistido las marcas producto, que buscan construir asociaciones simbólicas trasladando los aspectos característicos del estilo de vida londinense a su propia marca. Un estilo que oscila entre la imagen tradicional de la elegancia británica de toda la vida, al que recurren marcas como Hackett London o Burberry London, y que enseguida se asocia con los gentlemen ingleses, los estudiantes de Eton y Oxford o los sombreros y tocados del público de las carreras de caballos de Ascott, y que nada tiene que ver con la imagen de la ciudad con la que se vinculan marcas producto más vanguardistas como Merc London o Rimmel London, 
que prefieren el Londres bohemio de los mercadillos que aún conservan algunos rasgos de los movimientos contraculturales de los sesenta y setenta (movimientos hippie, mod,...) que invadían sus calles.

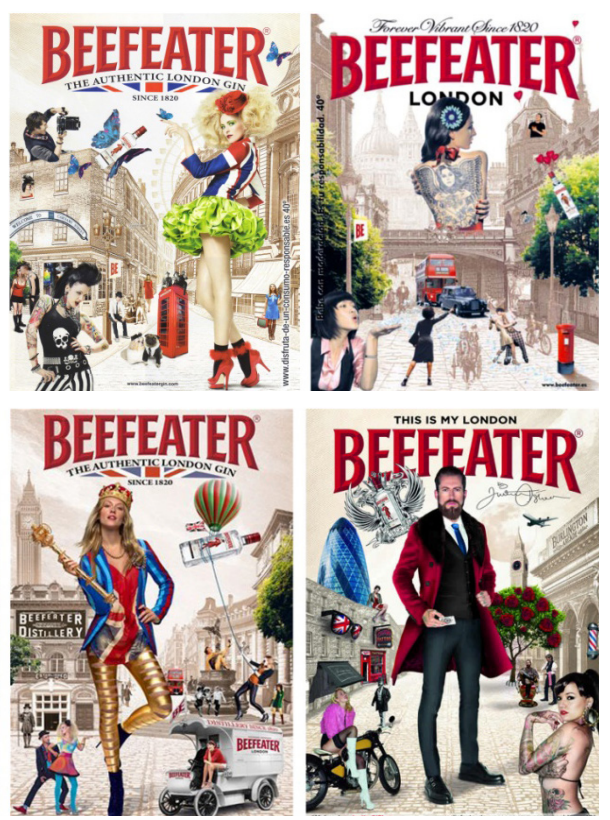

Figura 4. Campañas de publicidad de Beefeater London en las que se hace referencia tanto al estilo clásico londinense como al más vanguardista.

Fuente: http://algosucedenuestrasmentes.files.wordpress.com/2013/02/15.jpg

\section{CONCLUSIONES}

Las marcas ciudad, hoy en día plenamente consolidadas, proveen de un valor económico, social y cultural añadido a las ciudades. Su construcción implica estrategias de marketing y branding a largo plazo que van más allá de las meras acciones de promoción turística y que pretenden promocionar la proyección externa de la ciudad y posicionarla adecuadamente, al mismo tiempo que satisfacen las necesidades de todos sus públicos.

Por ello, en la gestión de la marca ciudad, su alianza con las marcas producto se presenta como una alternativa eficaz para generar sinergias que favorezcan la consecución de objetivos comunes.

No obstante, los beneficios que aportan estas uniones, en la mayoría de las ocasiones median- te la fórmula del respaldo por nombre vinculado, son posibles solo si ambas marcas se complementan entre sí, de forma que resultan más atractivas y aumentan su credibilidad en sus respectivos mercados. Por el contrario, el principal inconveniente reside en que si la experiencia de consumo con alguna de las marcas involucradas no es satisfactoria, la otra marca también se verá afectada negativamente, de ahí la importancia de la selección de la marca con la que aliarse.

Algo a lo que deben prestar especial atención las autoridades locales responsables de la gestión de las marcas ciudad, que deben analizar en profundidad los riesgos vinculados a cada propuesta de asociación. Es evidente que una de las ventajas de la asociación marca producto/marca ciudad es el ahorro en costes para el Ayuntamiento de la ciudad si se alía con una marca comercial con la notoriedad suficiente, puesto que sus productos se convierten automáticamente en objetos promocionales de la propia ciudad y, su distribución, en la acción de sampling más económica que se pueda planificar. Pero aún así, no siempre compensa.

No hay que olvidar tampoco que las ciudades que gestionan su marca están más solicitadas por las marcas comerciales para este tipo de uniones de respaldo. Y es que las ciudades que han seguido un proceso de brandificación como Nueva York, Londres o París se han dotado de un extenso imaginario que ayuda a comercializar otras marcas gracias a la construcción de un estilo de vida propio y fácilmente reconocible.

Pero para que estas asociaciones puedan ser productivas y exitosas a corto y, sobre todo, a largo plazo, deben construirse a modo de alianzas estratégicas entre la ciudad y el producto, creando una línea comunicativa conjunta en la que ambas marcas se impliquen por igual.

Y es que este tipo de uniones no pueden limitarse a una acción de naming en la que el nombre de la ciudad y la marca producto figuren juntas sin más, puesto que no se trata de usar palabras que estandaricen conceptos, sino de crear significados y connotaciones específicas para cada marca. No basta con palabras, se buscan significados. 


\section{BIBLIOGRAFÍA}

AAKER, David. Managing Brand Equity: capitalizing on the value of brand name, Free Press, New York, 1991.

AAKER, David. y Joachimisthaler, Erich. Liderazgo de marca, Ediciones Deusto S.A., Bilbao, 2001.

Agencia de Turismo del Estado de Nueva York. "I love New York". Disponible en: [http://www.iloveny.com/] Última consulta el 15 de noviembre de 2014.

ALCAIDE, Juan Carlos y CHÁVARRI, Iñigo. "El comarketing como arma de presente y estrategia de futuro", Marketing y Ventas para Directivos, Año XXIV, no 260 (2010), pp. 8-18.

AMENDOLA, Giandomenico. La ciudad postmoderna, Celeste Ediciones, Madrid, 2000.

ANHOLT, Simon. "Mito y Realidad: La imagen internacional de México", Revista Mexicana de Política Exterior, no 96 (2012), pp. 109-129.

BAKER, Bill. "Places: The New Brand Frontier", Total Destination Management, July-August (2007), pp. 38-39.

BLAIN, C., LEVY, S.E. y BRENT RITCHIE, J.R. "Destination Branding: In sights and Practices from Destination Management Organizations". Journal of Travel Research, n0 43 (2005), pp. 337.

BLACKETT, Tom. Co- branding: the science of alliance, McMillan Press Ltd., London, 1999, pp. 97-124.

Boletín Oficial del Ayuntamiento de Madrid (2011, 4 de mayo). Sede electrónica del Ayuntamiento de Madrid. Gestiones y trámites. Disponible en: [http:// www.madrid.es/portales/munimadrid/es/Inicio/ Ayuntamiento/Boletin-Oficial-del-Ayuntamiento/ Buscador-Boletines/1055-Subvenciones-sector-moda2011?vgnextfmt=default\&vgnextoid=2581db5fa4b9f210 VgnVCM2000000c205aOaRCRD\&vgnextchannel=7a698 db0ae967010VgnVCM1000009b25680aRCRD]. Última consulta el 15 de noviembre de 2014.

CERVIÑO FERNÁNDEZ, Julio. Marketing internacional. Nuevas perspectivas para un mercado globalizado, Ediciones Pirámide (Grupo Anaya, S. A.), Madrid, 2006.

CERVIÑO FERNÁNDEZ, Julio y CRUZ ROCHE, Ignacio. "Las alianzas de marcas como fenómeno de marketing estratégico: un modelo conceptual de evaluación y análisis", Cuadernos aragoneses de economía, Vol. 6, n० 2 (1996), pp. 317-343.

CERVIÑO FERNÁNDEZ, Julio, SÁNCHEZ HERRERA, Joaquín. y CUBILLO PINILLA, José María. "Made in Effect, Competitive Marketing Strategy and Brand Performance: An Empirical Analysis for Spanish Brands", Journal of American Academy of Business (Cambridge), Vol. 6, no 2 (2005), pp. 237-243.

CORRO GARCÍA-LOMAS, Ignacio del. "Alianzas estratégicas entre marcas", Marketing y Ventas para
Directivos, Año XVIII, no 188 (2004), pp. 34-37.

DACHEVSKY, Marcelo. Urban Zapping. Ciudades, productos y marcas, Universitat Politécnica de Catalunya, S.L., Barcelona, 2001.

DESAI, K. K. y KELLER, K. L. "The Effects of Ingredient Branding Strategies on Host Brand Extendibility", Journal of Marketing, no 66 (2001), pp. 73-93.

doi: http://dx.doi.org/10.1509/jmkg.66.1.73.18450

DE ELIZAGARATE, Victoria. Marketing de ciudades. Ediciones Pirámide (Grupo Anaya, S. A.), Madrid, 2008.

DOWLING, Grahame. Corporate reputations: strategies for developing the corporate brand, Kogan Page, London, 1994.

FOMBRUN, Charles. Reputation: Realizing Value from the Corporate Image, Harvard Business School Press, Boston, 1996.

GARCÍA, José Sixto. "Marketing para ciudades: las ciudades también se venden, las ciudades también son productos", Pensar la Publicidad, Vol. 4, no 1 (2010). pp. 211-226.

GIRARD, M. "States, diplomacy and image making: what is new? Reflections on current British and French experiences". Ponencia presentada en la Conferencia sobre Imagen, Estado y Relaciones Internacionales. London School of Economics, 24 de junio de1999.

Guía Turística de Nueva York en español. "Campaña de promoción turística de Nueva York", 2007. Disponible en: [http://www.guiadenuevayork.com/noticia.php?t=11] última consulta el 12 de diciembre de 2014

HATCH, Mary Jo y SCHULTZ, Majken. "Bringing the corporation into corporate branding", European Journal of Marketing, Vol. 37, no 7/8 (2003), pp. 1041-1064.

HUERTAS, Assumpció. "Les claus del Citybranding". Portal de la Comunicació In-Com de la Universidad Autónoma de Barcelona (UAB), 2011.

KAVARATZIS, Michalis. "From city marketing to city branding: Towards a theoretical framework for developing city brands", Place Branding, Vol. 1, no 1 (2004), pp. 58-73. doi:10.1057/palgrave.pb.5990005

KOTLER, Philip. Dirección de marketing. Madrid: Prentice Hall, Madrid, 2000.

KOTLER, P., HAIDER, D. H. y REIN, I. Mercadotecnia de localidades, Diana, México, 1993.

Loreto Florián M. y Sanz, Gema. "Evolución de la terminología del marketing de ciudades", Universidad de Alcalá, Madrid, 2005, pp. 3-6.

Mango Blog: Keep the beat. "El Ayuntamiento de Barcelona y Mango promocionan la marca Barcelona", 2008, 23 de septiembre. Disponible en: [http://keepthebeat.mango.com/tag/mangobarcelona/?lang=es] Última consulta el 12 de octubre de 2014. 
MATEO, M. C. "Londres: gestión de la marca-ciudad". Ideas IE, no 99, pp. 16-17.

Marketing News.es. "Primera campaña de Londres como destino turístico en su cuenta atrás para el 2012", 2008, 2 de septiembre. Disponible en: [http://www. marketingnews.es/varios/noticia/1040971028705/ primera-campana-londres-destino.1.html] última consulta el 13 de noviembre de 2014.

MARTíNEZ GÓMEZ, Antonio. "Planificación estratégica y la imagen de la ciudad". Ponencia presentada en el Primer Congreso City-marketing Elche '04, Elche, enero 2004.

MUÑIZ MARTÍNEZ, Norberto y CERVANTES BLANCO, Miguel. "Marketing de ciudades y place branding", Pecvnia, Monográfico (2010), pp. 123-149.

MUÑOZ CARROBLES, Diego. "Los estereotipos urbanos a través de la publicidad turística", Revista de Filología Románica, Anejo VI, no 2 (2008), pp. 43-46.

OLINS, Wally. "How brands are taking over the corporation" en HATCH, Mary Jo; SCHULTZ, Majken; LARSEN, M.H. (Eds.). The Expressive Organization, Oxford University Press, Oxford, 2000, pp. 51-65.

Park, C. W., Jun, S. Y. y Shocker, A. D. "Composite Branding Alliances: An Investigation of Extension and Feedback Effects", Journal of Marketing Research, Vol. 33, no 4 (1996), pp. 453-466. doi: http://dx.doi. org/10.2307/3152216

Oficina de Turismo y Congresos de París. "Paris Info", 2014. Disponible en: [http://es.parisinfo.com/] Última consulta el 14 de octubre de 2014.

Oficina de Turismo y Congresos de París. "40 ans de Tourisme à Paris", 2014. Disponible en: [http://asp.zonesecure.net/v2/index.jsp?id=1203/1515/15714\&lng=fr] última consulta el 24 de octubre de 2014.

Oficina Nacional de Turismo Británico. VisitEngland, 2014. Disponible en: [http://www.visitengland.com/es/ES/] Última consulta el 12 de octubre de 2014.

Oficina de Turismo de Londres. VisitLondon, 2014. Disponible en: [http://www.visitlondon.com/es/] Última consulta el 12 de octubre de 2014.

PricewaterhouseCoopers, LLP. "Informe Cities of Opportunity 2014", 2014. Disponible en: [http://www. reputationinstitute.com/frames/events/2013_City_ RepTrak_Press_Release.pdf] Última consulta el 19 de noviembre de 2014.

Saffron Consultants. "London: Putting the world's greatest city back on top", 2013. Disponible en: [http:// www.saffron-consultants.com/our-work/london] Última consulta el 9 de noviembre de 2014.

Seisdedos, Hermenegildo. "La marca ciudad como antídoto para la "bonsainización" del "city-marketing", Harvard-Deusto Marketing \& Ventas, Vol. septiembreoctubre, no 76 (2006), pp. 72-77.
SIMOES, C. y DIBB, S. "Rethinking the brand concept: New brand orientation", Corporate Communications: An International Journal, Vol. 6, n04 (2001), pp. 217-224. doi: http://dx.doi.org/10.1108/13563280110409854 SIMONIN, B. L. y RUTH, J. A. "Is a Company Known by the Company It Keeps? Assessing the Spillover Effects of Brand Alliances on Consumer Brand Attitudes", Journal of Marketing Research, no 35 (1998), pp. 30-42. doi: http:// dx.doi.org/10.2307/3151928

TORREBLANCA DÍAZ, F., LORENTE SAN JUÁN, F., LÓPEZ TORTOSA, R., BLANES NADAL, C. y JUÁREZ VARÓN, D. "Comarketing como herramienta estratégica empresarial", 3C Empresa, Investigación y pensamiento crítico, no 10 (enero 2013), pp. 1-14.

VILLAFAÑE, Justo. La gestión profesional de la imagen corporativa, Ediciones Pirámide, Madrid, 1999.

VIRGO, B. y DE CHERNATONY, L. "Delphic brand visioning to align stakeholder buy-in to the city of Birmingham brand", Journal of Brand Management, Vol. 6, no 13 (2006), pp. 379-392. doi: http://dx.doi.org/10.1057/ palgrave.bm. 2540280

ZHOU, N. y BELK, R.W. "Chinese consumer readings of global and local advertising appeals", Journal of Advertising, Vol. 33, no 3 (2004), pp. 63-76. doi: http:// dx.doi.org/10.1080/00913367.2004.10639169

Zhuang, G., Whang, X. et al. "Asymmetric effects of brand origin confusion. Evidence from the emerging market of China", International Marketing Review, Vol. 25, no 4 (2008), pp. 441-457. 